\title{
Acupuncture as a Modality for Treating Anxiety Related Disorders in Canines
}

\section{Kontogianis $\mathrm{K}^{*}$, Greene S and Fanucchi L}

Department of Veterinary Clinical Sciences, Washington State University College of Veterinary Medicine, USA

*Corresponding author: Kristin Kontogianis, Doctor of Veterinary Medicine (DVM) and Certified Veterinary Acupuncturist (CVA), Pet Medical Center of Pasco, 8823

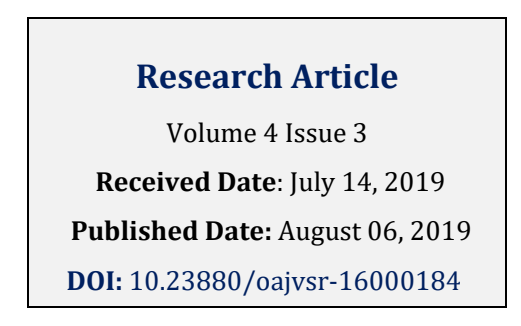

Sandifer Parkway, Pasco, Washington (WA), USA, Tel: 509-545-4931; Kristin.Kontogianis.DVM@gmail.com

\section{Abstract}

Canine anxiety is a common behavior disorder that may manifest as aggression or violent behaviors and often culminates in animal surrenders. While there are scientifically supported behavior protocols available today, behavior problems are still a major concern for many dog owners. Thus, this case study series sought to explore an additional potential treatment modality, acupuncture. Four case reports were completed; they included two client-owned dogs and two shelter dogs. All dogs presented because of anxiety and aggression. Questionnaires completed by the pet owner throughout the study, heart rates before and after treatment, and researchers' observations were used to compare the dog's pre- and post-acupuncture behaviors. While the client-owned dogs were reported to have decreased anxiety and aggression, the shelter dogs were reported to have very little to no improvement in anxiety or aggression. This study was limited by the small sample size, the subjective nature of the data collected, the lack of a control group and the lack of blinding. Further research is needed to determine if acupuncture has significant therapeutic potential for canine anxiety; ideally, future studies would include a larger sample size and quantifiable data such as blood serotonin measures, endogenous opioid levels, or cortisol measures. Alternatively, future studies may include a control group and double blinded design.

Keywords: Veterinary Medicine; Acupuncture; Behavior; Anxiety; Aggression; Dogs

\section{Introduction}

Of the approximately 70 million dogs living in United States (USA) households, behavioral abnormalities including canine anxiety and aggression are not uncommon $[1,2]$. More than 4.5 million people in the USA are bit by dogs each year, with children being the most common victims and dogs, with no previous bite history towards children, being the most common offenders [2,3]. Risk factors associated with dog bites towards children are typically resource guarding by the dog and/or paininducing actions by the child towards the dog, such as 
hitting [2]. The American Veterinary Medical Association (AVMA) claims that "the majority of these bites, if not all, are preventable," yet the number of reported, annual dog bites has been rather consistent for over a decade $[1,4]$. Furthermore, many cases of canine anxiety do not present as bites towards humans. Separation anxiety, noise phobia (fear of loud sounds), and combinations of behavioral-disorders are common ailments in veterinary medicine, and as many as 35 million dogs in the USA are suspected to have suffered from separation-related problems (vocalization, destruction of property and inappropriate elimination when alone) at some point in their life-time; behavior problems (such as hyperactivity, destruction of house-hold furnishings, biting, fearfulness, and barking) are also leading contributors to the approximately 3.9 million dogs surrendered to shelters each year [5-8]. Thus, while dog bites towards humans are arguably the most devastating outcome of canine anxiety; the problem greatly extends beyond the bite statistics.

Traditional preventative treatments, like basic training and neutering, have not been found to consistently decrease behaviors related to canine anxiety and aggression in every case [2]. Current treatments include pharmacologic intervention and behavior modification (scientifically supported training methods such as positive reinforcement) [9]. These approaches have been suggested to be notably effective, yet the population of dogs with anxiety is devastatingly high $[1,9,10]$. Whether it be an individual dog's lack of response to behavior medications, contraindications of treatment, or additional/unknown factors, there are limitations to the current treatment plans. Furthermore, it has been proposed by veterinary behaviorists that "a holistic approach is needed to address all the issues that may have an impact on the pet's behavior;" a multi-modal treatment plan is a highly used protocol in behavior medicine [11].

Because of the commonality and level of difficulty associated with treating canine anxiety, this study sought to explore an additional treatment modality, acupuncture. Participating dogs underwent a series of acupuncture treatments, during which owners completed questionnaires subjectively measuring their dog's progression of elicited behaviors over time. It was hypothesized that acupuncture would decrease canine anxiety after six consecutive, weekly treatments; it was also predicted that: 1) owner perceived manifestations of anxiety, such as aggression, self-mutilation/destructive behaviors, inappropriate urination, and vocalization/lunging during walks, would decrease; 2) heart rates after treatment compared to before treatment would be lower; and 3) researchers would notice an increased ease of acupuncture treatments as the study progressed.

\section{Review of Canine Anxiety and Current Treatment Options}

\section{Anxiety: Manifestations, Pathophysiology and Neurotransmitters}

Anxiety is most commonly the result of fear: an aversive state of the nervous system that presents as apprehensive worry, general nervousness, and tension, which animals perceive as a threat to their safety [12]. Symptoms include jumpiness or reactivity, excessive vigilance or obsessive-compulsive disorder (OCD) tendencies, gastrointestinal disturbances (such as diarrhea), frequent urination, and aggression; tachycardia also occurs secondary to fear/anxiety and pain $[7,12,13]$.

Anxiety and its symptoms are the result of complex interactions of different neurodynamics; associated neurotransmitters include, but are not limited to, serotonin (5-HT), $\beta$-endorphins, dopamine, substance $\mathrm{P}$, norepinephrine and acetylcholine $[9,14,15]$. Serotonin is recognized by many to be the most relevant neurotransmitter in behavior medicine as it reduces "cross-talk" between sensory channels and is thought to increase a dog's ability to learn $[9,12,14]$. $\beta$-Endorphins (endogenous opioid neuropeptides and peptide hormones) are associated with pain and social feelings and when present in high enough concentrations, can counteract homeostatic imbalances and induce pleasure [14]. Dopamine is part of the SEEKING system and is associated with reward-based learning (such as positive reinforcement or providing rewards for good behavior, i.e. food); it maintains psychomotor and motivational focus and arousal and is inhibited by chronic stress, sickness, and depression $[9,14,16]$. Substance $P$ is associated with pain and anger; it facilitates transmission of noxious inputs and activates glial cells in response to painful stimuli, and its release is inhibited by opioids and endorphins $\quad[9,12,14,17]$. Norepinephrine and acetylcholine maintain signal/noise ratios in sensory processing areas and mediate attention and arousal in sensory systems respectively [14].

\section{Current Treatment Options for Canine Anxiety}

Modern pharmacologic intervention affects various aforementioned neurochemicals and is a major component of current behavior protocols; it is typically 


\section{Open Access Journal of Veterinary Science \& Research}

prescribed in addition to behavior modification $[9,18]$. The intent is to enhance animals' ability to learn by altering their perception of various stimuli $[9,15,18]$. Pharmacologic intervention will not teach dogs to "sit," but it may decrease their responsiveness to unwanted distractions, better allowing them to focus, learn and remember the task at hand $[9,15,18]$.

Current treatments typically target the aforementioned diffuse modulatory neurotransmitters, including serotonin, dopamine, norepinephrine, and acetylcholine [9]. Medications that increase available serotonin include monoamine oxidase inhibitors (MAOIs), selective serotonin reuptake inhibitors (SSRIs), and tricyclic antidepressants (TCAs) [9]. MAOIs work via multiple routes as they inhibit the breakdown of norepinephrine, dopamine, and serotonin [9]. SSRIs and TCAs are more serotonin specific (with SSRIs being more specific than TCAs even); these are examples of daily medical management of canine behavior disorders $[9,18]$. Fluoxetine (an SSRI) is a widely prescribed behavioral medication [18]. One comparative study found fluoxetine to have a significant effect on canine separation anxiety and compulsive disorders, including spinning, tail-chasing, lick granulomas, and pacing [10]. Anxious dogs when compared to non-anxious dogs have also been shown to be less proactively engaged and to display more signs of stress while problem-solving [19]. Fluoxetine may benefit these animals, as another study reported that fluoxetine propagated "less negative" cognition bias in treated pets [8]. Before the availability of fluoxetine, TCAs were commonly prescribed. TCAs were the first effective medication for panic attacks in people and the first substantial reducer of vocalization associated with separation anxiety in dogs [20]. Behavior medications also include GABA agonists like benzodiazepines [9]. At low doses, benzodiazepines act as mild sedatives and at moderate doses, they act as anxiolytics; however, benzodiazepines can also cause paradoxical excitability, and in cases where the fear response is one of avoidance, can increase canine aggression $[9,18]$. Benzodiazepines can also be hepatotoxic, and it is important to monitor the patient's blood chemistry values regularly [9]. Additional treatments include situational or as-needed medications (such as single dose treatment for noise phobia). Trazodone is a serotonin 2A antagonist reuptake inhibitor; while it can be used on an as-need basis, it can also be prescribed as an adjunctive treatment to unresponsive patients [9]. Neuroleptics, which block dopamine receptors and include phenothiazine tranquilizers like acepromazine, have also been widely prescribed for tranquilization on an as-need basis, such as for transportation [9]. Side effects of acepromazine include dysphoria, ataxia, muscle tremors/discomfort, impairment of normal balance and potentially increased aggression and sensitivity to sound; while a decreased seizure threshold is frequently reported, there appears to be no evidence to support such a claim [9,21]. Benzodiazepines are typically preferred over neuroleptics in cases where immediate control of anxiety is needed but should be used with caution in aggressive animals as they may decrease bite inhibition $[9,18]$.

Though far less commonly prescribed for canine anxiety, medications with opioid agonists may also be beneficial. A 1998 study found a reduction in canine separation distress vocalizations associated with low doses of opioids; a dose-response analysis, where very low doses of morphine were administered to 6-8 weekold-puppies, was included [20]. Since the role of pain in canine anxiety is often confusing, the analgesic effects may also be of benefit to some animals [18]. It has been found that opioid administration may be beneficial in the treatment of self-mutilation, like acral lick dermatitis [9]. Furthermore, while opioids are not commonly used to treat canine behavior disorders, they have been used in people. Opioids have long been known for their antidepressant properties when used in very low doses [22]. A serious limitation to prescription opioids for canine anxiety though is human abuse potential and liabilities associated with the "opioid abuse epidemic" $[22,23]$. Tramadol has also been postulated as potentially effective in combating behavior disorders (particularly in cases where pain may be a component) as it has three synergistic effects: opiate agonist; inhibition of norepinephrine reuptake; and inhibition of serotonin reuptake [18]. It has elicited significant behavior changes in some studies performed on research animals and people [18]. While tramadol (or less controlled opioid-like drugs) may be more appropriate for treating canine anxiety than true opioids, veterinary clinical studies exploring the behavioral therapeutic effects in dogs are insufficient to support its use at this time, and there is still human abuse opportunity/risk [18,22,23].

Lastly, non-prescription drugs such as: L-theanine, tryptophan, pheromone and combination therapies are available and can be used as an adjunctive to the prescription drugs [11].

Even though behavior medications have been found to be quite effective in many instances, there are limitations with the current treatment modalities such as potential adverse side-effects, and/or individual intolerance or unresponsiveness $[9,18,22]$. Thus, the goal of this study was to explore the potential of an additional 
treatment modality in hopes to better serve veterinary patients and to treat more canines suffering from anxiety.

\section{Acupuncture as a Potential Treatment Modality}

\section{Acupuncture as a Modality to Treat Canine Anxiety and Aggression}

This is not the first study to propose acupuncture as a treatment modality for psychological disorders. Studies have reviewed its ability to treat depression and anxiety in people, and treatments with acupuncture have been proposed and anecdotally reported in canine patients [2428]. While some suggest that it reduces canine aggression, anxiety, behavioral anorexia, depression and compulsive disorders (like obsessive overgrooming/self-mutilation), there are currently no controlled studies that support this hypothesis $[11,28]$.

Previous studies have suggested that acupuncture may be as effective as TCAs; however, most literature reviews suggest that while acupuncture may serve as a treatment modality for psychological disorders, more research is needed due to the widely inconclusive results and interpretations $[11,24,25,29,30]$. Thus far, studies exploring the efficacy of acupuncture as a treatment modality are poorly designed when standardized to the Western contexts of experimental design and research quality $[24,30]$. Nonetheless, acupuncture is still widely used to treat anxiety and depression in people [31].

While research concerning the effectiveness of acupuncture to treat psychological disorders is inconclusive thus far, some studies have shown that electroacupuncture (EA) blocks pain via peripheral, spinal and supraspinal mechanisms and can increase endogenous opioid and serotonin concentrations [17]. Specifically, $\mu$ - and $\delta$-opioid receptors, which are activated with EA, inhibit substance $P$, which as aforementioned, is associated with pain and anger [17]. Additionally, a review from 1982 reported that cyproheptadine and cinanserine (serotonin blockers) significantly reduced the serotonin induced analgesic effects of acupuncture in rabbits and rats respectively, and that naloxone (reversal agent for opioids) partially reversed the analgesic effects of EA; reversal of acupuncture analgesia by 0.05-0.1 $\mathrm{mg} / \mathrm{kg}$ naloxone was almost complete at a frequency of 2 hertz $(\mathrm{Hz})$ and was partial at $80 \mathrm{~Hz}$ [32]. At different frequencies, EA induces different neurotransmitters: low frequency EA (2-6 Hz) induces central release of opioids and endorphins, while high frequency EA $(100-200 \mathrm{~Hz})$ induces release of serotonin, epinephrine and norepinephrine; EA has also been found to accelerate the rate of synthesis and utilization of 5-HT in the brain and spinal cord [13,32]. Thus, although these studies were framed in a different context and performed on different species, EA/acupuncture has been shown to have an effect on the diffuse modulatory neurotransmitters associated with canine anxiety.

In addition to direct concentrations of circulating neurotransmitters in animal models, studies have also looked at more readily operant or measurable physiologic indications of situational anxiety in people, such as blood pressure, pulse rates, and palmar sweating [29]. While these physiological changes have been measured in several studies, they do not necessarily correlate with reported changes in anxiety scores, and most conclusions are based off subjective assessments [31]. In veterinary medicine, heart rates are rather commonly assessed and accepted in studies as an indication of canine anxiety $[7,33]$.

Lastly, a recent review of the research on use of opioids to treat refractory depression concluded that low doses of the opioid buprenorphine can effectively treat depression disorder in human patients that do not respond to conventional antidepressants, psychotherapy or both, with satisfactory tolerance for the drug and no major side effects [22,34]. However, the risks for development of treatment-resistant depression with long term opioid use has been investigated, and as previously discussed, there is a serious risk for human abuse potential $[23,35]$. In that regard, acupuncture's effect on endogenous opioids could pose a significant benefit, as humans would not have access to such forms. However, if acupuncture's main mechanism of action for anxiety related disorders is a significant increase in endogenous opioids, it is worth considering the possibility for development of resistance to acupuncture's effects in the long-term use of this treatment modality. Thus, while the benefits of medications affecting serotonin and opioids for behavior disorders have been supported in research, the limitations associated with each are significant and even prohibitive in some instances. Further exploring the feasibility of acupuncture as a treatment will be an important long-term consideration if shown to be an effective treatment as well.

\section{Case Study Series Research Design}

\section{Hypothesis}

Previous studies supporting acupuncture's ability to increase circulating concentrations of serotonin, opioids, 
and other diffuse modulatory neurotransmitters, as well as studies measuring heart rate as an indirect indication of canine anxiety, served as justification for this study. Researchers hypothesized that acupuncture could effectively decrease canine anxiety as measured by predicted reductions in: 1) anxiety as reported by owners via questionnaires; 2) post- versus pre- treatment heart rates; and 3) researcher reported difficulty of treatment.

\section{Methods}

This was a case study series based on observations made primarily by pet owners in the home environment, with supplemental pre- and post- treatment heart rates and researchers' annotations conducted during the acupuncture sessions; "owners" refers to both pet owners and shelter staff throughout. Shelter dogs were volunteered by the staff of the Whitman County Humane Society (WCHS) after reviewing the recruitment email and Client Information Sheet; shelter animals had permission to participate via a letter of consent from the WCHS board of directors. Additionally, privately owned dogs were recruited via email sent to students and staff at Washington State University (WSU) and the Pullman, Washington (WA) and Moscow, Idaho (ID) community.

To meet the criteria for participation, owners must have been at least 18 years old, signed the Informed Consent Form and agreed to the requirements of the study; dogs must have had up-to-date Rabies vaccinations with no history of cancer. Owned dogs were to be housed at their private residence, while shelter dogs were to be housed at the WCHS. Owners were required to transport their dog to and from the WSU Veterinary Teaching Hospital (VTH) for the treatments; boarding at the VTH before or after treatments was not permitted.

This study was approved by the Institutional Animal Care and Use Committee (IACUC) and had an Institutional Review Board (IRB) exemption. The treatments were performed at the WSU VTH, in the Behavior Room, $1706 \mathrm{AB}$. The treatment room was ten feet, eleven inches by twenty-one feet, six inches. Acupuncture appointments were made by owners via a doodle poll; responses were hidden and could only be seen by the researchers.

A complete treatment consisted of a minimum of six weeks and a maximum of ten, with appointments occurring weekly. During treatments, acupuncture needles designated for dogs (Jing Tang Sterile Acupuncture Needles ${ }^{\circledR}$, Gauge $32 \#$ x $1.0^{\prime \prime}=0.25 \mathrm{~mm} \times$ $25 \mathrm{~mm}$ ) were inserted through the skin and into the underlying tissue at indicated acupuncture points (acupoints); in some cases, EA was performed using the Jing Tang JT-1A Electro-Acupuncture Stimulator ${ }^{\circledR}$.

All appointments were scheduled to last one hour; treatments occurred between October $11^{\text {th }}, 2016$ and March $7^{\text {th }}, 2017$. The procedures for each appointment in chronological order were as follows unless stated otherwise in the Case Reports and Results section of this paper. The owner arrived, checked in at the VTH front desk and completed any paperwork required. Researchers then greeted the dog and owner in the VTH lobby and offered each owner the opportunity to be present for treatment. They discussed any concerns or questions with the owner and ensured the owner signed the Informed Consent Form before the dog began treatment. A paper identification collar (with the dog's randomly assigned identification letter and project ASAF number) and standard slip lead were secured around the dog's neck; any additional collars, leashes, etc. were removed. Pedal heart rate data were assessed via the AliveCor Vet ${ }^{\circledR}$, a portable electrocardiogram (ECG) adapter for the iPhone ${ }^{\circledR}$. Once in the treatment room, researchers observed the animal's behavior and provided treats (Pup-Peroni ${ }^{\circledR}$ and/or owner provided treats) and positive interactions. A complete physical exam was performed and sterile acupuncture needles (approximately five to twenty per dog per visit) were placed; the chosen acupoints were adjusted as needed. In cases without contraindications, EA was added at appropriate frequencies (less than or equal to $120 \mathrm{~Hz}$ depending on desired hormonal response) and treatments were maintained for at least fifteen minutes. Once complete, acupuncture needles were removed and discarded into the treatment room's sharps container acupuncture needles were used only once. A posttreatment heart rate was acquired via the same methods as were used for the pre-treatment measure. If the owner did not choose to be present for the treatment, the dog was returned to him/her in the lobby. Researchers answered any final questions; the owner replaced the dog's original articles and returned the standard slip lead, thus concluding the appointment.

During each treatment, dogs had access to water. Manual restraint was performed by the researchers, or if deemed appropriate, willing owners were asked to gently restrain their dog. This was not a requirement, and owners had the right to not restrain their own animal. Other than the methods described above, no additional behavior modification was initiated as part of the study, and any preexisting pharmacologic intervention was continued. 
Questionnaires written by a fourth-year veterinary student/corresponding author, and reviewed by researchers, were completed by owners throughout the study. Before the first treatment, owners were emailed and completed the Demographic Information Form, the Behavior and Medical Background Questionnaire, the scheduling link, and Informed Consent Form. During appointments two through six/nine, the owner completed the Treatment Questionnaire. Thus, each owner completed five to eight Treatment Questionnaires, depending on the number of treatments chosen. Lastly, the Conclusion Questionnaire was emailed to, and completed and returned by, the owner approximately one week after the final treatment. In the end, researchers should have had a minimum of seven questionnaires per dog reporting any observed changes in the subject's behavior during the study.

The questionnaires included a combination of Likert Scales, multiple-choice, select all that apply and short answer response (comments). When owners provided multiple scores to a single select question, the higher, or more negative score was reported. For example, Dog C's questionnaires frequently had two values circled on Likert Scale questions, such as 3 and 4 or 4 and 5; in these cases, the higher value was reported ( 4 and 5 respectively) as half scores were not included in this study. This method of selecting the score weighted more negatively was employed throughout the study.

Additionally, heart rate data were analyzed via Excel (in Microsoft Office 2013 Professional Plus $®$ ) as a single factor analysis of variance (ANOVA) (Appendix 1). Researchers' notes were compiled at the end of each treatment. Dogs were identified via a randomly assigned letter, instead of their names.

\section{TCVM Diagnosis and Acupoint Selection}

In Eastern medicine or Traditional Chinese Veterinary Medicine (TCVM), diseases, pain, and behavior problems are the result of an imbalance within the body $[11,13]$. Specifically, behavior problems are typically caused by "Shen disturbances" or an imbalance of the animal's mental-emotional state $[15,26]$. Shen disturbances present the same way as "generalized anxiety" cases do in Western medicine: difficulty training, inappropriate elimination, startled by loud noises or sudden movements, restlessness, easily frightened, destruction of inanimate objects or self-mutilation, hyperactivity/mania, etc. [5$8,26]$. However, different from Western medicine, in TCVM, common ailments present from unique imbalances and require individualized treatment plans $[15,27]$.
In this study, acupoints were chosen based on history, assessed TCVM diagnosis and physical exam findings. The cases represent a holistic evaluation of acupuncture as a treatment rather than specific acupoints being assessed for their effect.

Since all participants presented for anxiety/Shen disturbances, many of the acupoints were similar; furthermore, in efforts to create an individualized Eastern treatment plan while conforming to Western scientific standards, some points were repeated between dogs. Each dog had one to two acupoints specific to their presentation and four to five shared points, as listed in the Case Reports and Results section (Figure 1). Ability to successfully place acupuncture needles in the desired acupoints was dependent on the dog's willingness to allow treatment. Acupoints reside on "meridians" or "channels." The following acupoints on the Governing Vessel (GV), Heart (HT), Bladder (BL), Stomach (ST) and Gallbladder (GB) Channels were chosen for the listed reasons:

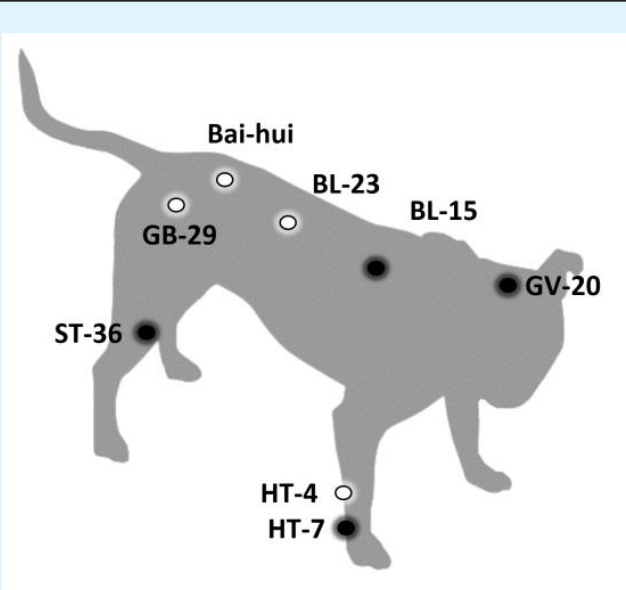

Figure 1: Acupoints used in this study; in the case reports below, an asterisk $\left({ }^{*}\right)$ following the acupoint indicates that needles were placed bilaterally; black circles indicate acupoints assigned to, but not necessarily successfully maintained for the intended duration in, all cases; white circles indicate case specific points.

- GV-20 (Cranial Bai-hui or Permission Point): is typically placed first due to its sedative effects; it may be used to treat Shen disturbances and sleep disorders [36,37].

- Bai-hui: is similar in action to GV-20 and was used in cases where placement of GV-20 was not possible [37].

- HT-7: is a very common point used to treat Shen disturbances, anxiety, restlessness, behavioral 


\section{Open Access Journal of Veterinary Science \& Research}

problems, sleep disorders and mania; this channel is also responsible for mental/Shen health [15,26,36,37].

- BL-15: is the Back-shu association point for the Heart and is used to treat Shen disturbances, cognitive dysfunction, and sleep disorders [36,37].

- ST-36: is the master point for GI tract/abdomen and stimulates hindlimb mobility [36]. This point "tonifies qi" (increases energy flow), is the Rear limb 3 mile point (encourages exercise and mobility of the hind end), and was hypothesized by researchers of this study to have a potential secondary effect to reduce Shen disturbances, as a holistic protocol for canine anxiety also commonly includes exercise to "consume" surplus energy [36,38,39]. Furthermore, a 2014 study postulated that EA at ST-36 (Zusanli) might decrease inflammation via downregulation of tumor necrosis factor alpha (TNF- $\alpha$ ) [40]. Researchers of the present study also hypothesized that ST-36 could be beneficial in treating behavior cases where inflammatory pain contributed to anxiety.

- BL-23: is the Back-shu association point for the Kidney and is commonly used to treat urinary incontinence and pelvic limb weakness/coxofemoral osteoarthritis [36].

- HT-4: is a less commonly used point but is indicated to treat Shen disturbances, sleep disorders, anxiety and restlessness [36].

- GB-29: is used for coxofemoral osteoarthritis, pelvic limb paresis and gluteal muscle pain; GB acupoints are commonly used for tendon/ligament health [36].

\section{Case Reports and Results}

\section{Subject Selection}

Over thirty people responded to the recruitment email expressing interest in the study. Factors limiting canine enrollment were the inflexible schedule and the inability to house canines at the VTH before or after treatments. Four dogs (two client-owned and two shelter) enrolled in the six-week study. Although Dog J missed her Treatment 3 and only had five total treatments, the other three dogs completed the six-week study. Though not a requirement, none of the dogs had received acupuncture prior to this study.

\section{Heart Rates}

Each dog's heart rate was taken before and after treatment (Table 1). However, a heart rate was unattainable during Dog J's Treatment 1 due to her severe aversion to pedal palpation/extremity manipulation.

\begin{tabular}{|c|c|c|}
\hline $\begin{array}{c}\text { Dog - Treatment } \\
\text { Number }\end{array}$ & $\begin{array}{c}\text { Pre-Treatment } \\
\text { Heart Rate }\end{array}$ & $\begin{array}{c}\text { Post-Treatment } \\
\text { Heart Rate }\end{array}$ \\
\hline C - & 109 & 104 \\
\hline $\mathrm{C}-2$ & 170 & 125 \\
\hline $\mathrm{C}-3$ & 127 & 125 \\
\hline $\mathrm{C}-4$ & 119 & 113 \\
\hline $\mathrm{C}-5$ & 101 & 99 \\
\hline $\mathrm{C}-6$ & 152 & 122 \\
\hline $\mathrm{V}-1$ & 113 & 87 \\
\hline $\mathrm{V}-2$ & 133 & 91 \\
\hline $\mathrm{V}-3$ & 67 & 110 \\
\hline $\mathrm{V}-4$ & 74 & 89 \\
\hline $\mathrm{V}-5$ & 108 & 101 \\
\hline $\mathrm{V}-6$ & 124 & 124 \\
\hline $\mathrm{V}-7$ & 63 & 83 \\
\hline $\mathrm{V}-8$ & 118 & 132 \\
\hline $\mathrm{V}-9$ & 158 & 129 \\
\hline $\mathrm{Q}-1$ & 108 & 113 \\
\hline $\mathrm{Q}-2$ & 125 & 119 \\
\hline $\mathrm{Q}-3$ & 168 & 89 \\
\hline $\mathrm{Q}-4$ & 111 & 65 \\
\hline $\mathrm{Q}-5$ & 189 & 145 \\
\hline $\mathrm{J}-6$ & 105 & 134 \\
\hline $\mathrm{J}-1$ & - & - \\
\hline $\mathrm{J}-3$ & 171 & 122 \\
\hline $\mathrm{J}-4$ & - & - \\
\hline $\mathrm{J}-5$ & 133 & 122 \\
\hline $\mathrm{J}-6$ & 129 & 119 \\
\hline $\mathrm{N}-6$ & 115 & 99 \\
\hline
\end{tabular}

Table 1: Heart Rates.

Dog J's pre- and post- treatment heart rates at subsequent treatments (excluding the cancelled Treatment 3) were acquired by placing the AliveCor Vet $\AA$ to her left thorax for ten seconds. Post- minus pre-treatment heart rates provided the difference (Table 2).

\begin{tabular}{|c|c|c|c|c|c|c|}
\hline Treatment & $\mathbf{1}$ & $\mathbf{2}$ & $\mathbf{3}$ & $\mathbf{4}$ & $\mathbf{5}$ & $\mathbf{6}$ \\
\hline Dog C & -5 & -45 & -2 & -6 & -2 & -30 \\
\hline Dog V & -26 & -42 & 43 & 15 & -7 & 0 \\
\hline Dog Q & 5 & -6 & -79 & -46 & -44 & 29 \\
\hline Dog J & & -49 & & -11 & -10 & -16 \\
\hline
\end{tabular}

Table 2: Heart Rate Changes (Post - Pre-Treatment Heart Rates).

An ANOVA: Single Factor analysis was performed for the heart rate data for Treatments 1-6 (a total of 22 paired heart rates). The P-value for the data was $0.76(>0.05)$ and was not statistically significant (Appendix 1); though the majority of individual heart rates were lower after 
treatment, no significant statistical difference was seen in the difference between pre- and post-treatment heart rates for any treatment.

\section{Case Reports}

\section{Dog C}

Dog C was a 2-year-old, female spayed (FS), Pit Bull Terrier; she was a shelter dog at WCHS. She presented for generalized and separation anxiety, inter-dog aggression and aggression towards people. She also had chronic diarrhea. Dog C had been assessed by the WSU Behavior Service veterinarian (Dr. Fanucchi) prior to the study. Dog C's prescribed medications at the time of enrollment included: fluoxetine $20 \mathrm{mg}$ in the $\mathrm{AM} ; 50 \mathrm{mg}$ trazodone in the AM; $100 \mathrm{mg}$ trazodone in the PM; and metronidazole $250 \mathrm{mg}$ in the AM and PM. She remained on all the medications minus metronidazole for the duration of the study. The owner hoped to see improvement in general and separation anxiety (Appendix 2).

On physical exam, Dog C had a broken canine tooth and fluctuating sensitivity on palpation cranial to BL-23*. Points chosen for Dog C were: GV-20, HT-7*, BL-15*, BL23*, and ST-36*. Because of her current pharmacologic intervention and behavior modification protocol, only dry needles were used; EA was not used in efforts to mitigate any potential risk of inducing serotonin syndrome. Furthermore, right HT-7 was not successfully placed for the desired fifteen minutes during Treatments 1-3; it was for Treatments 4-6.

\begin{tabular}{|c|c|}
\hline $\begin{array}{c}\text { Questionnaires/Behavior: } \\
\text { Behavior and Medical Background Questionnaire: } \\
\text { Behavior occurs: }\end{array}$ \\
\hline \multicolumn{2}{|c|}{ Constantly } \\
\hline $\begin{array}{c}\text { Treatment Questionnaires: } \\
\text { Since the start of the study, the behavior has: }\end{array}$ \\
\hline $\mathbf{1}$ & Not Changed \\
\hline $\mathbf{2}$ & Decreased \\
\hline $\mathbf{3}$ & Ended \\
\hline $\mathbf{4}$ & Decreased \\
\hline $\mathbf{5}$ & Decreased \\
\hline Conclusion Questionnaire: \\
Behavior occurs:
\end{tabular}

Table 3: Dog C's Anxiety.

The other eight points were successfully placed for all six treatments. BL-23 was selected for Dog C because of the reported problem of constant inappropriate urination (though the original answer was she sometimes elicited inappropriate urination, and the owner changed it to constantly); over the six-week study, this behavior was reportedly decreased (Table 3 ).

Throughout the study, the Treatment Questionnaire results were inconsistent and completed by different shelter staff (owners) as well as a foster volunteer; the foster volunteer participated in Dog C's Treatment 4 and completed the associated Treatment Questionnaire 3.

Throughout the duration of the treatments, Dog C appeared to have severe inter-dog aggression as seen by growling and lunging at other canines in the VTH lobby. Similar reports were made by owners (Appendix 2). Improvement during the car ride was reported on Treatment Questionnaire 2, though she was originally reported as riding in cars with ease (Appendix 2). Treatment Questionnaire 4 may have suggested some improvement (Appendix 2). Treatment Questionnaires also consistently reported strong reactivity to strangers entering the house/shelter, walking in public, and activity on the opposite side of the fence; her reactivity was mostly scored 4/5 (with 1 being not reactive and 5 being very reactive) throughout the study with no operant improvement seen in the numerical data. While the Conclusion Questionnaire reported a decrease in her overall anxiety, it also reported no change in her aggressive behavior (Appendix 2). Dog C was consistently reported as somewhat aggressive by the owner(s).

Researchers saw minimal improvement in this case; the reported improvement included increasing ease of placing right HT-7 and decreased tension to light restraint. Dog C was claimed from WCHS and returned to a previous owner shortly after completing this study.

\section{Dog V}

Dog V was a 7-year-old, FS, Border Collie mix; she was a client-owned dog. She presented for heightened anxiety and inter-dog aggression with resource guarding tendencies. Dog V had seen a dog trainer before but had not seen a veterinarian/behaviorist about these behaviors prior to enrollment; Dog V was not on any behavior medications, though she received one scoop of Platinum Performance CJ supplements (Equine Omega-3 Wellness and Performance Formula plus Complete Joint $($ ) by Platinum Performance twice daily. The owner hoped Dog $\mathrm{V}$ would be better able to go for walks and allow people into the home with decreased reactivity after participating in the study (Appendix 2). 
On physical exam, Dog V had a chronic lump along her right, third-lumbar vertebra (L3); the owner verbally reported this was a side effect of a previous trauma/hit by car incident. Points chosen for Dog V were: GV-20, HT-7*, BL-15*, HT-4*, and ST-36* (and BL-23* later in the study). HT-4 was chosen because of the various manifestations of anxiety reported. All points were successfully placed for fifteen minutes for all treatments. For Treatments 1-7, Right ST-36 was typically the most sensitive acupoint and was thus placed last. However, during Treatments 8 and 9, BL-23* was hypersensitive on palpation during the physical exam and was thus added to the treatment plan. EA at a frequency of $4 / 20 \mathrm{~Hz}$ was used for Treatments 2-9;
ST-36* and BL-15* were connected bilaterally for Treatments 2-7, and BL-15* and BL-23* were connected bilaterally for Treatments 8 and 9 .

The owner reported improvement in reactivity, anxiety and aggression after treatments (Appendix 2). On the Conclusion Questionnaire Dog V's reactivity was said to have decreased a lot (Appendix 2). Overall, the subjective, numeric data collected in the questionnaires supported a decrease in Dog V's reactivity to most stimuli, though her reaction to the doorbell and people entering the home was still severe/scored high (Figure 2).
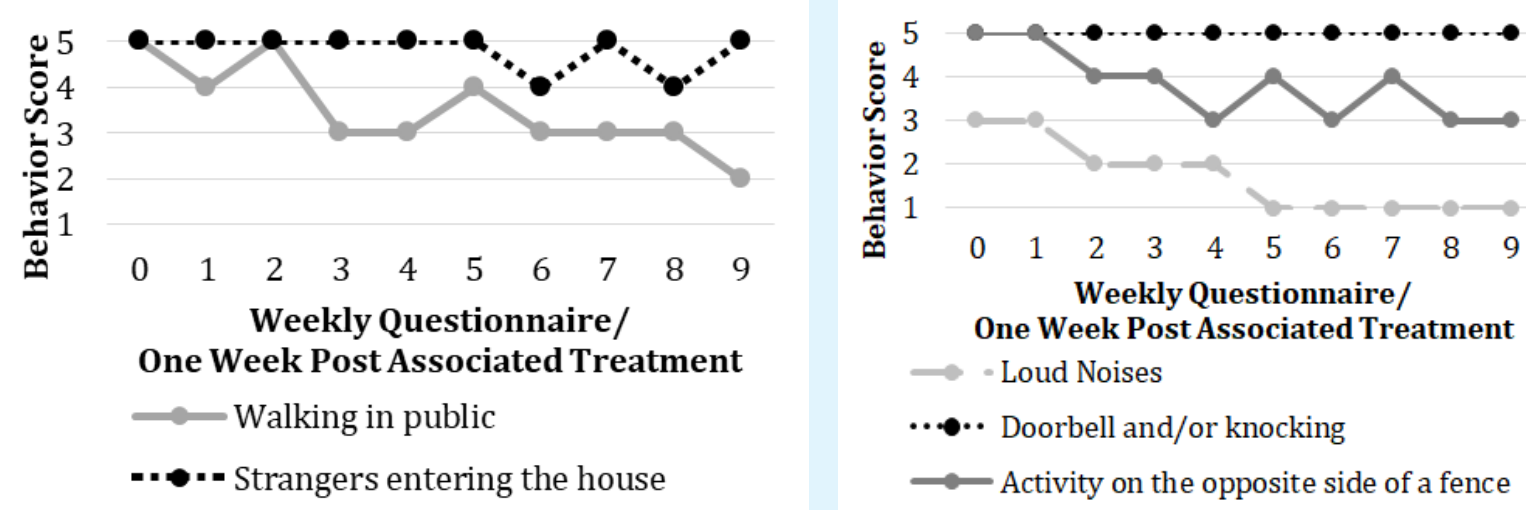

Figure 2: Dog V's reactivity as reported by the owner via weekly questionnaires, with 1 being not reactive and 5 being very reactive.

Through the questionnaires, the owner also reported a decrease in the challenge presented when walking Dog V; while her lunging at other dogs when on a leash had not changed/still occurred constantly, Dog V's lunging at people went from sometimes before the study to ended at completion of the study. Dog V also went from walking in remote, quiet areas before the study, to semi busy locations with more cars than people after a couple weeks in the study, to busy/loud locations for the last few weeks of the study. Via the questionnaires, the owner reported a decrease in Dog V's anxiety (including decreases in destruction of inanimate objects and self-mutilation) as well as a decrease in aggression (Table 4).

\begin{tabular}{|c|c|c|c|}
\hline Questionnaires/Behavior: & Destruction of objects & Self-mutilation & Aggression \\
\hline \multicolumn{4}{|c|}{$\begin{array}{c}\text { Behavior and Medical Background Questionnaire: } \\
\text { Behavior occurs/my dog is: }\end{array}$} \\
\hline & Sometimes & Sometimes & Frequently/ Aggressive \\
\hline \multicolumn{4}{|c|}{ Treatment Questionnaires: } \\
\hline & Since the start of the study, the behavior has: \\
\hline 1 & Not Changed & Decreased & Not Changed \\
\hline 2 & Decreased & Not Changed & Decreased \\
\hline 3 & Decreased & Decreased & Decreased \\
\hline 4 & Decreased & Decreased & Decreased \\
\hline 5 & Decreased & Increased & Not Changed \\
\hline
\end{tabular}




\section{Open Access Journal of Veterinary Science \& Research}

\begin{tabular}{|l|c|c|c|}
\hline 6 & Decreased & Decreased & Decreased \\
\hline 7 & Decreased & Not Changed & Decreased \\
\hline 8 & Decreased & Decreased & Decreased \\
\hline \multicolumn{4}{|c|}{$\begin{array}{c}\text { Conclusion Questionnaire: } \\
\text { Behavior occurs/my dog is: }\end{array}$} \\
\hline & Rarely & Rarely & Decreased/Somewhat Aggressive \\
\hline
\end{tabular}

Table 4: Dog V's Anxiety and Aggression.

The owner also commented on the decrease in frequency of behavior episodes throughout the study; furthermore, while the intensity of episodes seemed to remain high, the time to regain composure was reportedly decreased (Appendix 2).

Researchers noticed moderate improvement in ease of treating Dog V. During Treatment 6, she was more willing to interact with researchers and even sought their attention; also during this treatment a stranger entered the behavior/research room (with the "Do NOT Enter" research sign and IACUC number on the door), and the dog did not respond-no barking, lunging or attempting to remove herself from the EA was elicited.

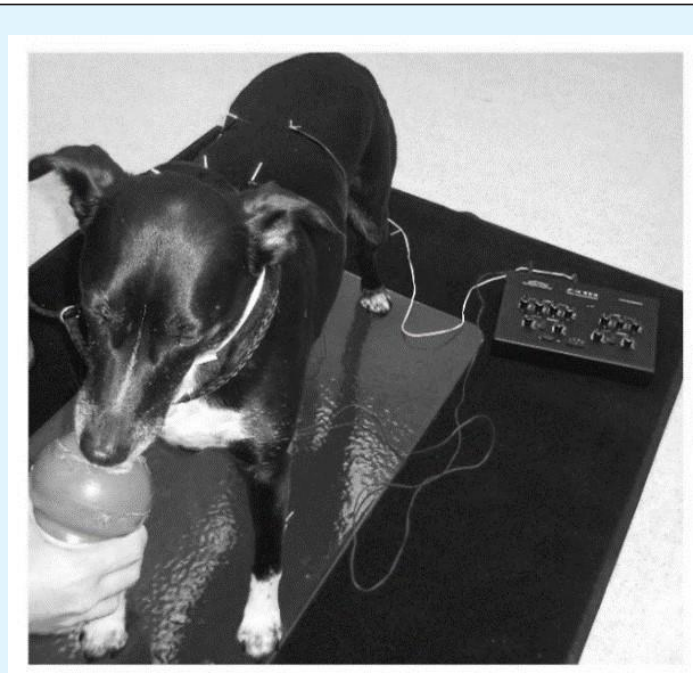

Figure 3: Dog V undergoing electro-acupuncture (EA) during her ninth and final treatment (when *BL-23 was added for EA between *BL-15 and *BL-23).
At Treatment 9 the researchers were warmly greeted by Dog V in the lobby; it was also noted that Dog V's attention was more readily redirected while walking to the treatment room. Dog V's ease of treatment had subjectively increased by the end of the study (Figure 3).

\section{Dog Q}

Dog Q was a 13-year-old, FS, Australian Shepherd; she was a client-owned dog. She presented for travel anxiety and aggression towards some people and other animals; their commute to participate in the study was three hours in each direction (six hours per appointment). Dog Q had seen a veterinarian for her travel anxiety prior to enrollment and was prescribed acepromazine; it was still being used during travel. She was also taking ThyroVet $\AA$ : $0.3 \mathrm{mg}$ two times per day. The owner hoped Dog Q would be better able to ride in the car by the end of the study (Appendix 2).

On physical exam, she had a lick granuloma on the dorsal, left metatarsals; it was an acute self-mutilation of about $3 \times 6 \mathrm{~cm}$ originally. Points chosen for Dog $Q$ were: GV-20, HT-7*, BL-15*, GB-29*, ST-36*. GB-29* was chosen because of her stiff gait in the hind limbs and suspected osteoarthritis of the coxofemoral joints. All points were successfully placed for fifteen minutes for all treatments. EA at a frequency of $4 / 20 \mathrm{~Hz}$ was used for Treatments 2-6; GB-29* and BL-15* were connected bilaterally.

Over the course of the study, the owners reported a decrease in Dog Q's anxiety, reactivity, and aggression, though she was consistently reported as somewhat aggressive, and her self-mutilations still occurred sometimes (Table 5 and Appendix 2).

\begin{tabular}{|c|c|c|c|}
\hline $\begin{array}{c}\text { Questionnaires/ } \\
\text { Behavior: }\end{array}$ & Aggression & Self-mutilation & \multirow{2}{*}{ Anxiety } \\
\hline \multicolumn{4}{|c|}{ Behavior and Medical Background Questionnaire: } \\
Behavior occurs/my dog is: & Not Applicable (N/A) \\
\hline & Sometimes/Somewhat Aggressive & Sometimes & Treatment Questionnaires: \\
\hline \multicolumn{4}{|c|}{ Since the start of the study, the behavior has: } \\
\hline
\end{tabular}




\section{Open Access Journal of Veterinary Science \& Research}

\begin{tabular}{|c|c|c|c|}
\hline 1 & Not Changed & Decreased & Decreased \\
\hline 2 & Decreased & Decreased & Decreased \\
\hline 3 & Decreased & Decreased & Decreased \\
\hline 4 & Decreased & Decreased & Decreased \\
\hline 5 & Decreased & Decreased & Decreased \\
\hline \multicolumn{3}{|c|}{ Conclusion Questionnaire: } \\
\hline & Since the study, the behavior has/my dog is/behavior occurs: & Decreased \\
\hline
\end{tabular}

Table 5: Dog Q's Anxiety and Aggression.

Regarding her aggression, the owner made several comments about her improvement via the questionnaires (Appendix 2). Questionnaires also reported an overall increased ease during walking and decreased barking, lunging at dogs, and lunging at people while walking (Table 6).

\begin{tabular}{|c|c|c|c|}
\hline Questionnaires/Behavior: & Barking & Lunging at people & Lunging at dogs \\
\hline \multicolumn{4}{|c|}{$\begin{array}{c}\text { Behavior and Medical Background Questionnaire: } \\
\text { Behavior occurs: }\end{array}$} \\
\hline & Sometimes & Rarely & Sometimes \\
\hline \multicolumn{4}{|c|}{ Treatment Questionnaires: } \\
\hline 1 & Not Changed & Decreased & Decreased \\
\hline 2 & Decreased & Decreased & Decreased \\
\hline 3 & Decreased & Ended & Ended \\
\hline 4 & Decreased & Ended & Ended \\
\hline 5 & Decreased & Ended & Ended \\
\hline \multicolumn{4}{|c|}{$\begin{array}{l}\text { Conclusion Questionnaire: } \\
\text { Since the study, the behavior has: }\end{array}$} \\
\hline & Decreased & Ended & Decreased \\
\hline
\end{tabular}

Table 6: Ease of Walking Dog Q.

Overall, the numeric data collected in the questionnaires supported a decrease in Dog Q's reactivity and anxiety; as the acupuncture treatments continued, Dog Q's reactivity associated with the car ride to the VTH had consistently decreased, though the owner did not circle an answer scoring the ease of the car ride to the
VTH on the Behavior and Medical Background Questionnaire - thus a score for Treatment 0 was not included for this graph; this question was also not included in the Conclusion Questionnaire as the dog did not travel to the VTH that week (Figure 4).
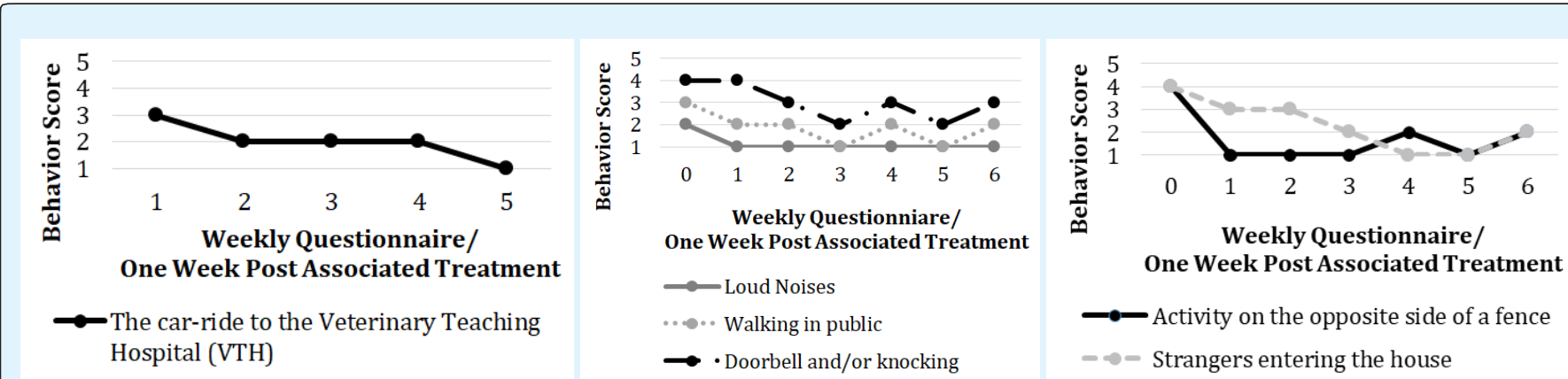

Figure 4: Dog Q's reactivity as reported by the owner via weekly questionnaires, with 1 being not reactive and 5 being very reactive. 
Additionally, during the study, the lick granuloma healed significantly, and she appeared to be selfmutilating less during the travels to appointments; during weekly physical exams, no new lick granulomas were found (Figure 5).

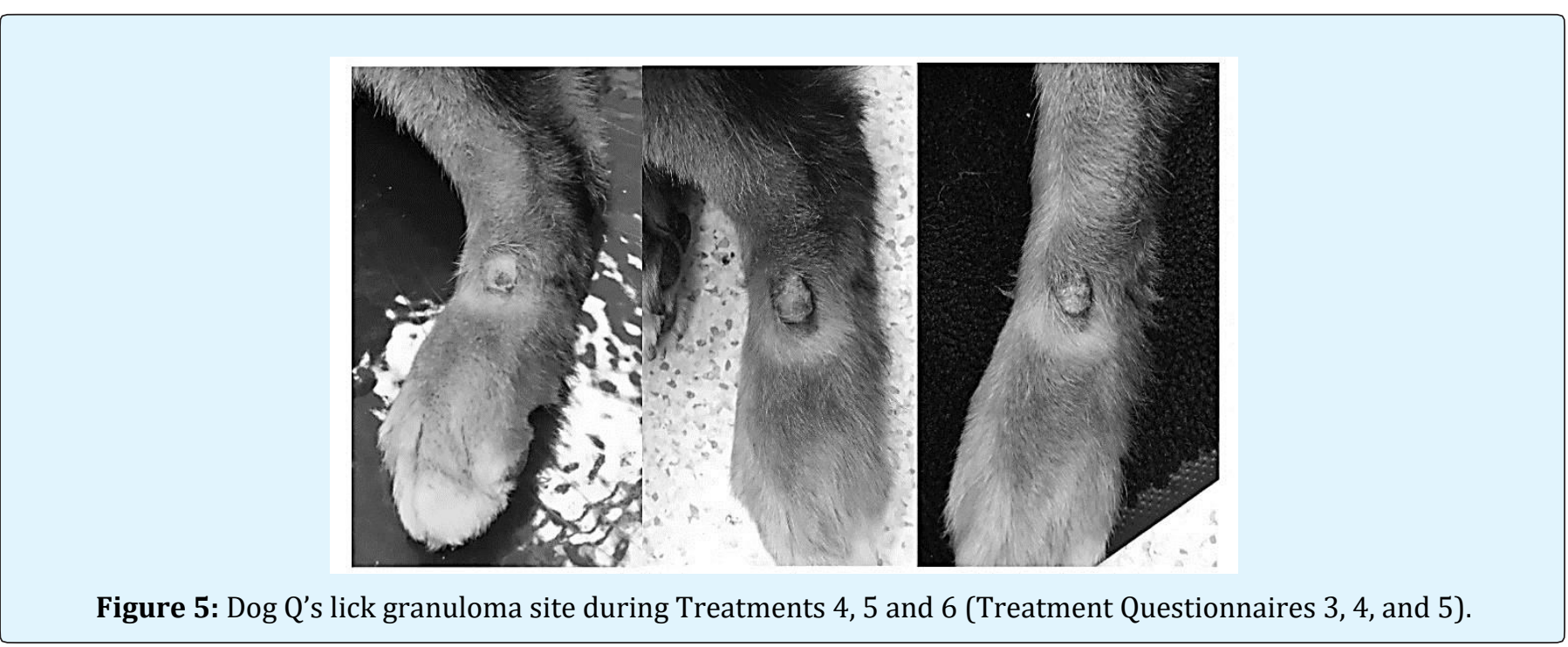

This was supported by the Treatment Questionnaires which consistently reported a decrease in self-mutilation (Table 5). For each treatment, two owners were present, and for Treatment 4, a third owner was present. Questionnaires were consistently completed by the same owner, who was reportedly pleased by the changes seen in Dog Q's behavior over the course of the study (Appendix 2).

Researchers also noticed a decrease in Dog Q's anxiety. Upon arrival in the lobby during Treatment 1, Dog Q was barking at another dog and was hesitant to interact with researchers; upon arrival in the lobby for Treatment 3 though, Dog Q was being pet and stared at by another VTH guest, who was a stranger to the dog. Additionally, a greater ease of placement of needles and ability to provide food rewards was observed. By Treatment 6 , the ease of EA treatments for Dog $Q$ were comparable to that of a geriatric dog. Minimal anxiety was appreciated, and once EA began, she tended to lie down and showed minimal to no signs of discomfort or stress (Figure 6).
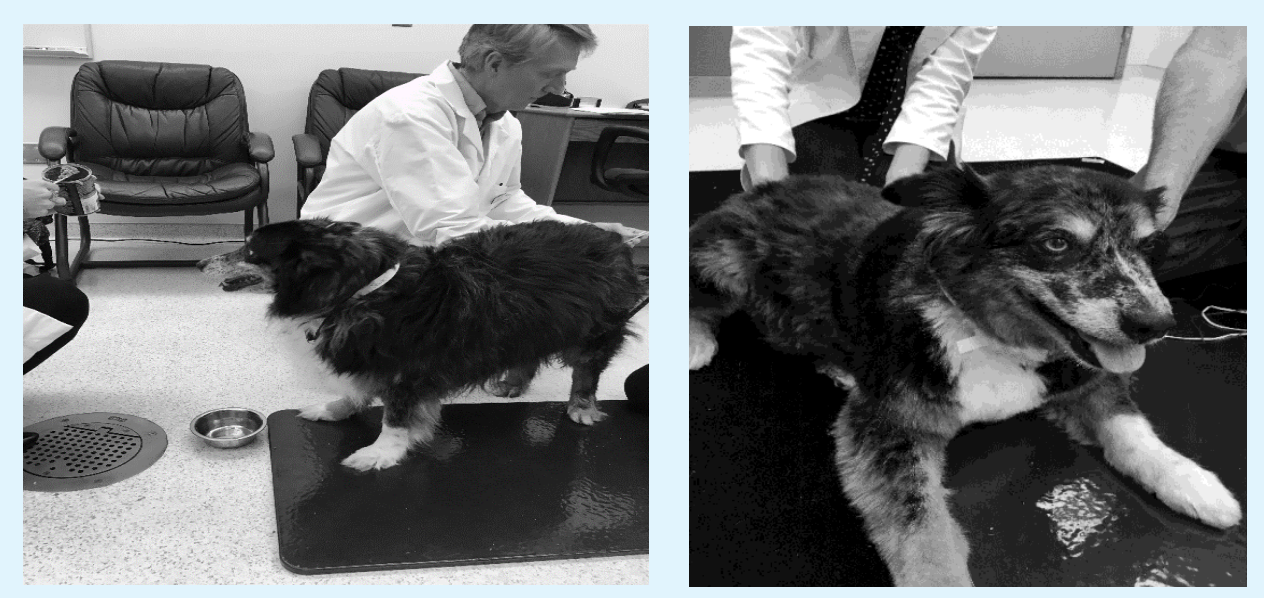

Figure 6: Dog Q receiving acupuncture at her first treatment (left) and electro-acupuncture (EA) at her fourth treatment (right). Note: She visited a groomer and had her hair cut between these visits. 


\section{Open Access Journal of Veterinary Science \& Research}

She was the only dog in this study to not receive consistent food rewards during treatment.

\section{Dog J}

Dog J was a 2-year-old, FS, Pit Bull; she was a shelter dog. Based on her history of attacking another dog, twice, she was declared a Dangerous Dog in the State of Washington. Because of this status, Dog J was met at the owner's car in the parking lot and went straight to the treatment room; she never entered the VTH lobby. She presented for severe inter-dog aggression and anxiety in the shelter. She was also reported as having a history of chronic diarrhea on the Behavior and Medical Background Questionnaire. Dog J had been discussed with the WSU Behavior Service veterinarian prior to enrollment. Dog J received Solliquin ${ }^{\circledR}$ by Nutramax Laboratories Veterinary Sciences, Inc. (L-theanine, magnolia/phellodendron, and whey protein concentrate) $1 \mathrm{~g}$ dog chew daily, starting approximately one week prior to enrolling in this study. She also received omega-3 fish oil capsules over her food. Due to her status, Dog J was required to wear a muzzle in public and during her treatments. The owner hoped Dog J would have a decrease in anxious behaviors seen at the shelter after treatment (Appendix 2).

On physical exam Dog J was very timid; no pain was appreciated. Points chosen for Dog J were: Bai-hui, BL15*, BL-23*, ST-36*, HT-7*; while the treatment plan was to include ST-36* and HT-7*, they were never successfully acupunctured during any treatment due to Dog J's severe hypersensitivity to touch and intolerance for manipulation of her extremities. Thus, Dog J was only treated with five needles each time. GV-20 also could not be used in this case because the muzzle strap interfered with the acupoint; Bai-hui was used instead. Dog J missed her third treatment and only completed five total treatments. Dry needles were used for Treatments 1 and 4. EA at a frequency of $80 / 120 \mathrm{~Hz}$ was used for Treatments 2, 5, and 6; BL-15* and BL-23* were connected bilaterally.

Treatment Questionnaires were inconsistent and incomplete; the Conclusion Questionnaire was approximately $60 \%$ complete, thus limiting the ability to compare changes before and after treatment. Overall, the questionnaires reported that there was no change in Dog J's anxiety, aggression or reactivity nearly $100 \%$ of the time; the numeric answers were consistently high (when provided, the scores for reactivity were almost always 4 and 5), and a lack of improvement was reported via comments (Appendix 2).

Researchers also did not notice any apparent improvements in Dog J's tolerance of acupuncture. She was still severely tense and would move away from treatments and handling throughout the duration of the study. While she appeared to be more tolerant during subsequent treatments, she was never compliant with acupuncture treatments.

In a follow-up email sent June $9^{\text {th }}, 2017$ from a different WCHS staff member than the one who completed the questionnaires, it was reported that Dog J started pharmacologic intervention: $20 \mathrm{mg}$ fluoxetine every 24 hours; she had been on it in addition to the daily Solliquin ${ }^{\circledR}$ chew since April $4^{\text {th }}, 2$ 2017. Since starting fluoxetine, the staff member reported via email that there was no noticed change in reactivity; she was still aggressive with dogs and some men, but her anxiety seemed reduced as she was licking herself less (Appendix 2).

\section{Overall}

From the four case reports, the two client-owned dogs were noted to have decreased anxiety, reactivity and aggression after treatment by both owners and researchers, while the two shelter dogs were concluded to have minimal to no improvement. While client-owned dogs would reference their owners and seemed to improve with treatment, shelter dogs did not. All dogs enrolled in this study had bitten a dog and/or person (Dogs V and Q had bitten people prior to enrolling in the study, while Dogs C and J had not - though the latter were shelter animals with unknown prior histories); no attempts to bite researchers or owners were made. Besides Dog J, no other dogs were muzzled during the study.

Additionally, the majority of dog owners (three out of four) reported a change in their dog's behavior after the study (Appendix 2). Furthermore, three out of four owners perceived acupuncture as a very good treatment for anxiety and were very likely to recommend acupuncture as a treatment to friends and family (Table 7). 


\section{Open Access Journal of Veterinary Science \& Research}

\begin{tabular}{|c|c|c|c|c|}
\hline Dog & $\begin{array}{c}\text { Overall experience with } \\
\text { the study }\end{array}$ & $\begin{array}{c}\text { Dog's overall } \\
\text { improvement from } \\
\text { start to finish }\end{array}$ & $\begin{array}{c}\text { Perception of } \\
\text { acupuncture as a } \\
\text { treatment modality }\end{array}$ & $\begin{array}{c}\text { Likelihood to recommend } \\
\text { acupuncture to friends/family }\end{array}$ \\
\hline C & 5 & 3 & 5 & 5 \\
\hline V & 5 & 5 & 5 & 5 \\
\hline Q & 5 & 4 & 5 & 5 \\
\hline J & 4 & 1 & 2 & 1 \\
\hline
\end{tabular}

Table 7: Owner's Impression of the Study with 1 being very poor and 5 being very good.

\section{Discussion}

It has been theorized that in the field of behavioral medicine, placebo effects of $50 \%$ or higher are not uncommon; thus, any supplement or medication that has not been systematically investigated and shown as statistically superior to a placebo, should be considered untested or unproven with respect to efficacy [11]. While the client-owned dogs (Dog V and Dog Q) seemed to show an acceptable level of improvement, the shelter dogs (Dog $\mathrm{C}$ and Dog J) showed very little to no improvement. From these four case reports, it is challenging to extrapolate whether or not acupuncture was an effective treatment for canine anxiety. Furthermore, there were many important limitations associated with this study; they include but are not limited to: the inability to separate change associated with the acupuncture itself versus the positive reinforcement (such as food rewards) during treatments; the pharmacologic intervention in some dogs (but not others) that could have affected the efficacy of acupuncture-induced endogenous chemical releases; a majority of the results were based on questionnaires answered by pet owners, thus potentially limiting their ability to accurately assess anxiety and change; both Western and Eastern methods were used which may have weakened or strengthened the potential effects of each; only female dogs enrolled in the study; the small sample size and lack of a control group decreased validity of generalizations made from results; the lack of blinding allowed for potential placebo effects - in client-owned cases the placebo effect could have falsely increased acupuncture's reported effectiveness, and with shelter dogs, the placebo effect could have falsely increased or decreased the reported efficacy as the shelter employees bringing the dogs and completing the questionnaires were not the ones who enrolled the dogs. Similar limitations associated with the methodology and experimental design have been reported in previous acupuncture-based studies [24,30,31].

Thus, like many previous studies exploring acupuncture as a potential treatment modality for behavioral disorders, it was found that more research is needed to better understand acupuncture as a treatment for canine anxiety.

Furthermore, while all four completed case reports are described in detail, the validity of the shelter dogs' data is quite poor and, while decidedly included in this study, could arguably be considered grounds for exclusion.

Firstly, Dog C's questionnaires were completed by different people, and her environment was unpredictably changed when she went to a multi-day foster in the middle of the study. Dog J's data were also substantially weak; not only did she miss a treatment and not complete the study as intended, but her questionnaires were also markedly incomplete. Neither shelter dog completed the study as it was designed; however, it was attempted to treat their anxiety with acupuncture, and thus their data were included. There are several hypotheses associated with each dogs' lack of responsiveness. Firstly, Dog C was the only dog not to receive EA and may have experienced different effects due to her already complete yet ineffective behavior protocol (fluoxetine and trazodone). Secondly, some hypotheses associated with Dog J's lack of reported response could include: her hypersensitivity to human touch; she was the only dog to miss one of her treatments; she was the only dog who wore a muzzle, which could have increased her stress level; she never experienced the effects of HT-7 while all the other dogs did; and she was treated with a different EA frequency, while the client-owned dogs were treated with $4 / 20 \mathrm{~Hz}$, she was treated with $80 / 120 \mathrm{~Hz}$ - she had no history of chronic pain, so a stimulation frequency that was expected to have a greater serotonin-releasing effect was chosen. Importantly, Dog J illustrated a significant limitation to treating anxious dogs with acupuncture; whether acupuncture is deemed an effective treatment or not, if the dog will not tolerate needles or restraint, this modality is likely to be ineffective/not feasible for such patients. 


\section{Open Access Journal of Veterinary Science \& Research}

As for the client-owned dogs, the overall improvement of problematic behaviors may be related to increased concentrations of circulating endogenous opioids and their inhibition of substance $\mathrm{P}$, cortisol, and/or epinephrine. However, more research measuring opioid levels, as well as stress hormones is needed to test this idea.

While acupuncture for client-owned dogs warrants further exploration, there are several limitations associated with a shelter setting that makes shelter dogs challenging animal models for studies of this nature. Some challenges are the limited resources of shelters, the jeopardized human-animal bond (HAB) between staff and shelter dogs, and the stressful shelter environment. Because the acupuncture treatments require much of the shelter's resources, there may be reason to believe that acupuncture is not an ideal treatment modality for them. With fluoxetine being an affordable everyday treatment, it might be more appropriate for shelter cases; unfortunately, pharmacologic intervention in both shelter cases did not appear to reduce either of the dog's anxiety and/or aggression to a desirable level, revealing the challenging nature of treating canine anxiety, especially in such an environment.

Even though the shelter dogs did not complete the study as intended, the lack of currently available data on acupuncture as a treatment modality for canine anxiety arguably makes their data worth sharing; contemplating the potential short-comings and limitations of their case reports will hopefully serve future studies by stimulating awareness, thought, and potentially future, well-designed experiments. Ideally, more studies comparing acupuncture to newer antidepressants like fluoxetine, or multi-model protocols including acupuncture in addition to pharmacologic intervention, will ensue [24].

Lastly, the number of people interested in participating in the study (approximately thirty), as well as the positive perception of acupuncture reported by three of the four dog owners in this study, suggests that there is interest from owners in this treatment modality. While resources were limited for this study, future studies that would be of more face validity would include: 1) blinding, which would be imperative to avoid owner bias and potential placebo effects; 2) greater sample size, which would be essential for statistical significance; 3) objective measurements, such as serum serotonin, serum endorphins or ethograms measuring the occurrence of specific behaviors over time, would be needed to better quantify and qualify the effects of acupuncture as a treatment.

\section{Conclusions and Recommendations}

Based on this study, veterinarians should not be discouraged from having honest discussions with interested owners and offering acupuncture as a potential treatment for canine anxiety, as long as the potential for minimal or no improvement in symptoms after treatment is discussed, as well as the possibility of animal refusal of treatments. While some dog owners reported no perceived therapeutic benefits, other owners did report noticeable improvement; thus, there is the potential that this treatment modality could help some dogs and owners struggling with canine anxiety. By offering holistic approaches to treat canine anxiety, veterinarians may more effectively reduce the incidence of undesirable behaviors and consequent surrenders of affected animals. Ideally, this study will serve the field of veterinary medicine by encouraging exploration of acupuncture as an additional treatment modality for canine anxiety.

\section{References}

1. American Veterinary Medical Association (2017) National dog bite prevention week.

2. Reisner IR, Shofer FS, Nance ML (2007) Behavioral assessment of child-directed canine aggression. Inj Prev 13(5): 348-351.

3. American Veterinary Medical Association (2017) Dog bite prevention.

4. Pappaioanou M (2004) Veterinary medicine protecting and promoting the public's health and well-being. Prev Vet Med 62(3): 153-163.

5. American Animal Hospital Association (AAHA) (2015) AAHA's behavior management guidelines aim to reduce relinquishment, euthanasia.

6. Storengen LM, Boge SCKB, Strom SJ, Loberg G, Lingaas F (2014) A descriptive study of 215 dogs diagnosed with separation anxiety. Appl Anim Behav Sci 159: 82-89.

7. Wormald D, Lawrence AJ, Carter GC, Fisher AD (2017) Reduced heart rate variability in pet dogs affected by anxiety-related behavior problems. Physiol Behav 168: $122-127$.

8. Karagiannis C, Burman OHP, Mills DS (2015) Dogs with separation-related problems show a "less pessimistic" cognitive bias during treatment with 


\section{Open Access Journal of Veterinary Science \& Research}

fluoxetine (Reconcile ${ }^{\mathrm{TM}}$ ) and a behavior modification plan. BMC Vet Res 11(80): 1-10.

9. Landsberg G, Hunthausen W, Ackerman L (2013) Pharmacologic intervention in behavioral therapy. In: Edwards R, Laing A, Watkins V, (Eds.), Behavior Problems of the Dog and Cat, $3^{\text {rd }}$ (Edn.), Saunders/Elsevier, Edinburgh, Great Britain, pp: 113138.

10. Irimajiri $M$, Luescher $A U$, Douglass $G$, RobertsonPlouch C, Zimmermann A, et al. (2009) Randomized, controlled clinical trial of the efficacy of fluoxetine for treatment of compulsive disorders in dogs. J Am Vet Med Assoc 235(6): 705-709.

11. Landsberg G, Hunthausen W, Ackerman L (2013) Complementary and alternative therapy for behavior problems. In: Edwards R, Laing A, Watkins V, (Eds.), Behavior Problems of the Dog and Cat, $3^{\text {rd }}$ (Edn.), Saunders/Elsevier, Edinburgh, Great Britain, pp: 139149.

12. Panksepp J (1998) The sources of fear and anxiety in the brain. In: Panksepp J, Davidson RJ, Ekman P, Scherer K, (Eds.), Affective Neuroscience: the foundation of human and animal emotions. Oxford University Press, 198 Madison Avenue, New York, USA, pp: 206-222.

13. Gaynor JS (2010) The physiology of pain and principles for its treatment. In: Bojrab MJ, Monnet E, Cann CC, Lazar T, (Eds.), Mechanisms of disease in small animal surgery, $3^{\text {rd }}$ (Edn.), Teton NewMedia, Jackson, Wyoming, USA, pp: 36-45.

14. Panksepp J (1998) Neurodynamics: neurochemical maps of the brain. In: Panksepp J, Davidson RJ, Ekman $P$, Scherer K, (Eds.), Affective Neuroscience: the foundation of human and animal emotions. Oxford University Press, 198 Madison Avenue, New York, USA, pp: 97-120.

15. Mayo E (2013) Behavioral disorders and acupuncture. American Journal of Traditional Chinese Veterinary Medicine 8: 49-55.

16. Panksepp J (1998) Seeking systems and anticipatory states of the nervous system. In: Panksepp J, Davidson RJ, Ekman P, Scherer K, (Eds.), Affective Neuroscience: the foundation of human and animal emotions. Oxford University Press, 198 Madison Avenue, New York, USA, pp: 144-163.
17. Zhang R, Lao L, Ren K, Berman BM (2014) Mechanisms of acupuncture-electroacupuncture on persistent pain. Anesthesiology 120(2): 482-503.

18. Sherman BL, Papich MG (2009) Drugs affecting animal behavior. In: Riviere JE, Papich MG, Adams HR, (Eds.), Veterinary Pharmacology and Therapeutics, $9^{\text {th }}$ (Edn.), Wiley-Blackwell, Iowa, USA, pp: 509-538.

19. Passalacqua C, Marshall-Pescini S, Merola I, Palestrini C, Previde EP (2013) Different problem-solving strategies in dogs diagnosed with anxiety-related disorders and control dogs in an unsolvable task paradigm. Appl Anim Behav Sci 147(1-2): 139-148.

20. Panksepp J (1998) Loneliness and social bond: the brain sources of sorrow and grief. In: Panksepp J, Davidson RJ, Ekman P, Scherer K, (Eds.), Affective Neuroscience: the foundation of human and animal emotions. Oxford University Press, 198 Madison Avenue, New York, USA, pp: 261-279.

21. Bednarski R, Grimm K, Harvey R, Lukasik VM, Penn S, et al. (2011) AAHA anesthesia guidelines for dogs and cats. J Am Anim Hosp Assoc 47(6): 377-385.

22. Bodkin AJ, Zornberg GL, Lukas SE, Cole JO (1995) Buprenorphine treatment of refractory depression. J Clin Psychopharmacol 15(1): 49-57.

23. Rauenzahn S, Fabbro ED (2014) Opioid management of pain: the impact of the prescription opioid abuse epidemic. Curr Opin Support Palliat Care 8(3): 273278.

24. Leo RJ, Ligot JSA (2007) A systematic review of randomized controlled trials of acupuncture in the treatment of depression. J Affect Disord 97(1-3): 1322.

25. Qu SS, Huang Y, Zhang ZJ, Chen JQ, Lin RY, et al. (2013) A 6-week randomized controlled trial with 4week follow-up of acupuncture combined with paroxetine in patients with major depressive disorder. J Psychiatr Res 47(6): 726-732.

26. Todd G (2016) Common behavior patterns: their diagnosis and treatment. In: Xie H, Ma A, (Eds.), Clinical Application of Different TCM Schools and Thoughts in Veterinary Practice; Proceedings of the 18th Annual International TCVM Conference. Chi Institute Press, 9650 West Hwy 318, Reddick, Florida, USA, pp: 137-142. 


\section{Open Access Journal of Veterinary Science \& Research}

27. Ferguson B (2016) Common canine behavioural problems and their treatment with a combination of acupuncture, TCVM herbal medicines and behavioural modification. In: Xie $\mathrm{H}, \mathrm{Ma} \mathrm{A}$, (Eds.), Clinical Application of Different TCM Schools and Thoughts in Veterinary Practice; Proceedings of the 18th Annual International TCVM Conference, Chi Institute Press, 9650 West Hwy 318, Reddick, Florida, USA, pp: 147-153.

28. Hsieh ML (2016) TCVM for the unusual cases of behavior problems in dogs and cats. In: Xie H, Ma A, (Eds.), Clinical Application of Different TCM Schools and Thoughts in Veterinary Practice; Proceedings of the 18th Annual International TCVM Conference, Chi Institute Press, 9650 West Hwy 318, Reddick, Florida, USA, pp: 167-173.

29. Pilkington K, Kirkwood G, Rampes H, Cummings M, Richardson J (2007) Acupuncture for anxiety and anxiety disorders - a systemic literature review. Acupunct Med 25(1-2): 1-10.

30. Goyatá SLT, Avelino CCV, Santos SVM, Souza Jr DI, Gurgel MDSL, et al. (2016) Effects from acupuncture in treating anxiety: integrative review. Rev Bras Enferm 69(3): 564-571.

31. Pilkington K (2010) Anxiety, depression and acupuncture: a review of the clinical research. Auton Neurosci 157(1-2): 91-95.

32. Han JS, Terenius L (1982) Neurochemical basis of acupuncture analgesia. Annu Rev Pharmacol Toxicol 22: 193-220.

33. King C, Buffington L, Smith TJ, Grandin T (2014) The effect of a pressure wrap (ThunderShirt ${ }^{\circledR}$ ) on heart rate and behavior in canines diagnosed with anxiety disorder. J Vet Behav 9(5): 215-221.

34. Stanciu CN, Glass OM, Penders TM (2017) Use of Buprenorphine in treatment of refractory depression
- A review of current literature. Asian J Psychiatr 26: 94-98.

35. Scherrer JF, Sala J, Sullivan MD, Schneider D, Bucholz KK, et al. (2016) The influence of prescription opioid use duration and dose on development of treatment resistant depression. Prev Med 91: 110-116.

36. Chrisman C, Xie H (2007) Canine Transpositional Acupoints. In: Xie H, Preast V, (Eds.), Xie's Veterinary Acupuncture, $1^{\text {st }}$ (Edn.), Blackwell Publishing, Ames, Iowa, USA, pp: 129-216.

37. Koh R (2016) How to treat sleeping disorder (insomnia) with TCVM. In: Xie H, Ma A, (Eds.), Clinical Application of Different TCM Schools and Thoughts in Veterinary Practice; Proceedings of the 18th Annual International TCVM Conference. Chi Institute Press, 9650 West Hwy 318, Reddick, Florida, USA, pp: 179181.

38. Hsieh ML (2016) Senior dog fear aggression treated with TCVM and behavior modification. In: Xie H, Ma A, (Eds.), Clinical Application of Different TCM Schools and Thoughts in Veterinary Practice; Proceedings of the 18th Annual International TCVM Conference. Chi Institute Press, 9650 West Hwy 318, Reddick, Florida, USA, pp: 163-164.

39. Hsieh ML (2016) Separation anxiety treated with TCVM and behavior modification in a dog. In: Xie H, Ma A, (Eds.), Clinical Application of Different TCM Schools and Thoughts in Veterinary Practice; Proceedings of the 18th Annual International TCVM Conference. Chi Institute Press, 9650 West Hwy 318, Reddick, Florida, USA, pp: 165-166.

40. Peng M, Li K, Wang C, Zhu X, Yang Z, et al. (2014) Therapeutic effect and mechanism of electroacupuncture at Zusanli on plasticity of interstitial cells of Cajal: a study of rat ileum. BMC Complement Altern Med 14(186): 1-10. 


\section{Appendices}

\section{Appendix 1: ANOVA Single Factor Analysis - Heart Rates}

Difference of Pre- and Post- Treatment Heart Rates for ANOVA: Single Factor

\begin{tabular}{|c|c|c|c|c|c|c|}
\hline Dog/Sample & $\begin{array}{c}\text { Treatment 1 (T1) } \\
\text { Column 1 }\end{array}$ & $\begin{array}{c}\text { T2 } \\
\text { Column 2 }\end{array}$ & $\begin{array}{c}\text { T3 } \\
\text { Column 3 }\end{array}$ & $\begin{array}{c}\text { T4 } \\
\text { Column 4 }\end{array}$ & $\begin{array}{c}\text { T5 } \\
\text { Column 5 }\end{array}$ & $\begin{array}{c}\text { T6 } \\
\text { Column 6 }\end{array}$ \\
\hline Dog C & 5 & 45 & 2 & 6 & 2 & 30 \\
\hline Dog V & 26 & 42 & -43 & -15 & 7 & 0 \\
\hline Dog Q & -5 & 6 & 79 & 46 & 44 & -29 \\
\hline Dog J & & 49 & & 11 & 10 & 16 \\
\hline
\end{tabular}

ANOVA Single Factor Analysis - Heart Rates

\begin{tabular}{|c|c|c|c|c|c|c|c|c|}
\hline \multicolumn{7}{|c|}{ Anova: Single Factor } & \multirow{2}{*}{\multicolumn{2}{|c|}{$\begin{array}{c}\text { Anova: Single Factor } \\
\text { Summary }\end{array}$}} \\
\hline \multicolumn{7}{|c|}{ Summary } & & \\
\hline Groups & Count & Sum & \multicolumn{2}{|c|}{ Average } & \multicolumn{2}{|c|}{ Varience } & Groups & Count \\
\hline Column 1 & 3 & 26 & \multicolumn{2}{|c|}{8.67} & \multicolumn{2}{|c|}{250.33333333} & Column 1 & 253.17 \\
\hline Column 2 & 4 & 142 & \multicolumn{2}{|c|}{35.5} & \multicolumn{2}{|c|}{395} & Column 2 & 410.75 \\
\hline Column 3 & 3 & 38 & \multicolumn{2}{|c|}{12.67} & \multicolumn{2}{|c|}{3806.33333} & Column 3 & 3811.17 \\
\hline Column 4 & 4 & 48 & \multicolumn{2}{|c|}{12} & \multicolumn{2}{|c|}{640.66667} & Column 4 & 644.67 \\
\hline Column 5 & 4 & 63 & \multicolumn{2}{|c|}{15.75} & \multicolumn{2}{|c|}{365.583333} & Column 5 & 371.46 \\
\hline Column 6 & 4 & 17 & \multicolumn{2}{|c|}{4.25} & \multicolumn{2}{|c|}{641.583333} & Column 6 & 641.71 \\
\hline \multicolumn{7}{|c|}{ Anova } & \multicolumn{2}{|c|}{ Anova } \\
\hline $\begin{array}{l}\text { Source of } \\
\text { variation }\end{array}$ & SS & $D f$ & $M S$ & $\mathbf{F}$ & P-Value & F crit & $\begin{array}{l}\text { Source of } \\
\text { variation }\end{array}$ & SS \\
\hline $\begin{array}{l}\text { Between } \\
\text { groups }\end{array}$ & 2317.44 & 5 & 463.49 & 0.52 & 0.76 & 2.85 & Between groups & -739.85 \\
\hline Within groups & 14241.83 & 16 & & 890.11 & & & Within groups & -8302.40 \\
\hline Total & 16559.27 & 21 & & & & & Total & -16517.27 \\
\hline
\end{tabular}

\section{Appendix 2: Comments Included in Questionnaires Completed by the Pet Owners}

\begin{tabular}{|c|c|l|}
\hline Dog & \multicolumn{1}{|c|}{ Questionnaire } & \multicolumn{1}{c|}{$\begin{array}{c}\text { Question (Q): } \\
\text { Comment (C)/Answer (A): }\end{array}$} \\
\hline C & $\begin{array}{c}\text { Behavior and Medical } \\
\text { Background Questionnaire }\end{array}$ & $\begin{array}{l}\text { Q2: What are your expectations regarding this treatment/study? } \\
\text { A: "Better general/[separation] anxiety." } \\
\text { C: "When people do not approach [Dog C] appropriately, she will lunge \& } \\
\text { bark. She is very dog selective \& reacts to most dogs." }\end{array}$ \\
\hline & Treatment Questionnaire (TQ) 1 & $\begin{array}{l}\text { C: “[Dog C was] focused on a husky which made it difficult to keep her } \\
\text { calm." }\end{array}$ \\
\hline & TQ 2 & $\begin{array}{l}\text { C: "She began lunging towards a Great Dane and barking... She is doing } \\
\text { much better in the car. She didn't whine/scratch at the crate as she has in } \\
\text { the past." }\end{array}$ \\
\hline TQ 4 & $\begin{array}{l}\text { C: “[Dog C] did really well with the two dogs she saw when I was checking } \\
\text { into her appointment. However, when we were getting ready to bring her } \\
\text { back into the treatment room, she was somewhat reactive to one of the }\end{array}$ \\
\hline
\end{tabular}




\begin{tabular}{|c|c|c|}
\hline & & $\begin{array}{l}\text { dogs in the lobby." } \\
\text { C: "She doesn't bite at the kennel door or whine as much as she did in the } \\
\text { beginning." }\end{array}$ \\
\hline & Conclusion Questionnaire & $\begin{array}{l}\text { Q: Since the start of the study, I noticed a change in my dog's behavior: } \\
\text { A: "Yes" } \\
\text { C: "[Dog C] seemed to be slightly improving with self-destructive behavior } \\
\text { and anxiety; however, the last two weeks of the treatment were a little } \\
\text { different. When she arrived back from foster, she seemed to be fairly } \\
\text { anxious. The day before the last treatment, she broke through the kennel } \\
\text { door and attacked another dog." } \\
\text { C: "[Dog C] is still very reactive to many dogs on walks." }\end{array}$ \\
\hline \multirow[t]{6}{*}{$\mathbf{V}$} & $\begin{array}{l}\text { Behavior and Medical } \\
\text { Background Questionnaire }\end{array}$ & $\begin{array}{l}\text { Q2: What are your expectations regarding this treatment/study? } \\
\text { A: "We would like to reach a point where we can go on walks without } \\
\text { getting so uptight about dogs around the area and have people enter my } \\
\text { house without her barking and going crazy." }\end{array}$ \\
\hline & TQ 1 & $\begin{array}{l}\text { C: "She has definitely had less "episodes" this week but when she is } \\
\text { reacting it is still at the same intensity level." }\end{array}$ \\
\hline & TQ 5 & $\begin{array}{l}\text { C: "I actually would say the [number] of times she gets aggressive has } \\
\text { decreased but when she gets worked up [it's] still the same intensity. She } \\
\text { does seem to calm down faster." }\end{array}$ \\
\hline & TQ 7 & $\begin{array}{l}\text { C: "I've been taking her to the dog park more because she has been doing } \\
\text { so well! And she is overall just calming down so much faster than she was } \\
\text { before!" }\end{array}$ \\
\hline & TQ 8 & $\begin{array}{l}\text { C: "She has been doing so much better with re-gaining her composure and } \\
\text { coming down from the more intense moments." }\end{array}$ \\
\hline & Conclusion Questionnaire & $\begin{array}{l}\text { Q: Since the start of the study, I noticed a change in my dog's behavior: } \\
\text { A: "Yes" } \\
\text { C: "[Dog V] has been letting me try [to clip] parts of her toenails.... She } \\
\text { seems more comfortable with being uncomfortable. She has also been } \\
\text { really good about adjusting to new situations... [and] she has been much } \\
\text { better about ignoring people when we go for walk[s] ([she is] still very } \\
\text { dog reactive but not as much [with] people!)." } \\
\text { C: "She is reacting less to motion outside the apartment." } \\
\text { C: "[Dog V] still reacts very uncontrollably to things regarding her space - } \\
\text { i.e. the mailman knocking on the door, deliveries, etc.... She seems much } \\
\text { more focused overall on our walks though, and tends to ignore other } \\
\text { people and activity and just wants to move!" } \\
\text { C: "[Dog V] has benefited tremendously from this study!... We have been } \\
\text { able to try dog parks again \& continue to interact with other people \& } \\
\text { other animals. Based on her energy levels, I do believe the acupuncture } \\
\text { was highly beneficial." }\end{array}$ \\
\hline \multirow[t]{4}{*}{$\mathbf{Q}$} & $\begin{array}{l}\text { Behavior and Medical } \\
\text { Background Questionnaire }\end{array}$ & $\begin{array}{l}\text { Q2: What are your expectations regarding this treatment/study? } \\
\text { A: "We like to take our dogs camping and [Dog Q] gets very anxious } \\
\text { whenever she rides in the car. I would like to see a reduction in her travel } \\
\text { anxiety." }\end{array}$ \\
\hline & TQ 1 & C: "[There] seemed to be less door licking in [the] car." \\
\hline & TQ 2 & $\begin{array}{l}\text { C: "She had a couple of episodes of barking at other dogs and children." } \\
\text { C: "Her participation in barking at people walking by the house has } \\
\text { decreased. Less barking when I or my wife leave the house." }\end{array}$ \\
\hline & TQ 3 & C: "She has barked at other dogs while walking this weekend but is easily \\
\hline
\end{tabular}




\begin{tabular}{|c|c|c|}
\hline & & $\begin{array}{l}\text { redirected. Some barking at my daughter's cats but minimal." } \\
\text { C: "Noticed reduced reaction to other dogs and cats." }\end{array}$ \\
\hline & TQ 4 & $\begin{array}{l}\text { C: "[Dog Q] still seems anxious on the first half of the trip to Pullman." } \\
\text { C: "[The] only observed aggression towards people was toward[s the] } \\
\text { postal person. A friend came in the house who [Dog Q] had never met and } \\
\text { she was social." } \\
\text { C: "Her reactivity to strange people has decreased." }\end{array}$ \\
\hline & TQ 5 & $\begin{array}{l}\text { C: "Less reactivity to other dogs and cats. Usually, she won't bark unless } \\
\text { the other dog barks first." }\end{array}$ \\
\hline & Conclusion Questionnaire & $\begin{array}{l}\text { Q: Since the start of the study, I noticed a change in my dog's behavior: } \\
\text { A: "Yes" } \\
\text { C: "[Dog Q] seems less anxious and more willing to tolerate other animals } \\
\text { and people." } \\
\text { C: "[Dog Q] is more accepting of other people and animals in her living } \\
\text { environment." } \\
\text { C: "[Dog Q's] aggressive behaviors have now decreased to a few specific } \\
\text { circumstances: protecting my wife, postal carrier[s] and herding cats. She } \\
\text { also reacts to a limited number of vehicles." } \\
\text { C: "Her lack of reaction to the strange people and animals in the house at } \\
\text { Thanksgiving was a pleasant surprise." } \\
\text { C: "Overall I have been pleased with the results from the study. I am now } \\
\text { interested in looking into acupuncture as a [treatment] for pain in both of } \\
\text { our aging dogs." }\end{array}$ \\
\hline \multirow[t]{5}{*}{ J } & $\begin{array}{c}\text { Behavior and Medical } \\
\text { Background Questionnaire }\end{array}$ & $\begin{array}{l}\text { Q2: What are your expectations regarding this treatment/study? } \\
\text { A: "Decrease in anxious behaviors seen at the shelter." }\end{array}$ \\
\hline & TQ 1 & $\begin{array}{l}\text { C: "[Dog J's] whining and pacing in [the] crate in car while still present is } \\
\text { improved this week." }\end{array}$ \\
\hline & TQ 2 & C: "No change in reactivity." \\
\hline & Conclusion Questionnaire & $\begin{array}{l}\text { Q: Since the start of the study, I noticed a change in my dog's behavior: } \\
\text { A: "No" } \\
\text { C: "Her history is that she is aggressive with other dogs and is anxious in } \\
\text { the shelter setting. This is seen through barking, pacing, jumping up the } \\
\text { walls, panting and [whining]. Since the start of the study we did not notice } \\
\text { a change in her behaviors. She continued to have marked anxiety in the } \\
\text { shelter and showed aggression towards other dogs." } \\
\text { C: "[Dog J] is not walked regularly due to her history of aggression and } \\
\text { listed as a dangerous dog in Washington State." }\end{array}$ \\
\hline & Follow-up Email From WCHS & $\begin{array}{l}\text { C: "I have not noticed any changes in regards to [Dog J's] reactivity since } \\
\text { starting her [on fluoxetine]... she is still aggressive towards other dogs and } \\
\text { some men. However, I have noticed that [Dog J] no longer licks herself } \\
\text { excessively/over grooms herself. Her general signs of anxiety/stress have } \\
\text { seemed to reduce." }\end{array}$ \\
\hline
\end{tabular}

